\title{
Article \\ Gamma-Ray Modified Polymer/Clay Composites: Synthesis, Characterization, and Formulation Optimization Using Multivariate Calculus and Graph Theory
}

\author{
Ahmed A. Bakhsh (D) \\ Department of Industrial Engineering, King Abdulaziz University, Jeddah 21589, Saudi Arabia; \\ aabakhsh@kau.edu.sa
}

check for updates

Citation: Bakhsh, A.A. Gamma-Ray Modified Polymer/Clay Composites: Synthesis, Characterization, and Formulation Optimization Using Multivariate Calculus and Graph Theory. Energies 2021, 14, 2724. https://doi.org/10.3390/en14092724

Academic Editor: Miriam Rafailovich

Received: 18 February 2021

Accepted: 6 May 2021

Published: 10 May 2021

Publisher's Note: MDPI stays neutral with regard to jurisdictional claims in published maps and institutional affiliations.

Copyright: (C) 2021 by the author. Licensee MDPI, Basel, Switzerland. This article is an open access article distributed under the terms and conditions of the Creative Commons Attribution (CC BY) license (https:// creativecommons.org/licenses/by/ $4.0 /)$.
Abstract: To enhance the oxidation strength and crosslinking yield of ultrahigh molecular weight polyethylene (UHMWPE), its composites were prepared by mixing $1 \%, 2 \%$, and $3 \%$ (by wt.) of magnesium silicate hydrous (sepiolite) during this study. These composites were irradiated with $25 \mathrm{kGy}$ and $50 \mathrm{kGy}$ of irradiation doses in the open air. Subsequent to irradiation, the composites were characterized for updates in structure, oxidation strength, and degree of crosslinking while estimating the values of oxidation index (OI), crosslink density (Gx), and percent crystallinity ( $\mathrm{Xc}_{\mathrm{c}}$, respectively. The reaction of modified sepiolite (SP) on irradiating UHMWPE/SP composites was evident from the origination of peaks at $\mathrm{Si}-\mathrm{O}, \mathrm{O}-\mathrm{Si}-\mathrm{O}, \mathrm{Si}-\mathrm{O}-\mathrm{Si}$, and $\mathrm{Mg}-\mathrm{OH}$ and stretching vibration at $974 \mathrm{~cm}^{-1}, 1014 \mathrm{~cm}^{-1}$, and $1080 \mathrm{~cm}^{-1}$, respectively. In addition, the moderate negative correlation of OI ( -0.46$)$ and strong positive correlation of Gx (0.87) with the absorbed dose, made obvious from correlation analysis, confirmed the effectiveness of SP in enhancing the oxidation strength and crosslink density of UHMWPE. Furthermore, cluster analysis (CA) grouped the composites as low, moderate, and best based on dissimilarities, i.e., oxidation strength and crosslink density, which was further confirmed by principal component analysis (PCA). PCA also revealed that the OI, Gx, and absorbed dose were the active variables for this best group. After confirming the effectiveness of SP (as an active filler for enhancing the oxidation strength and crosslink density of UHMWPE) and recognizing the OI, Gx, and absorbed dose as active variables, the next step was to determine the necessary minimum amount of SP concentration and radiation dose required for the composite that outperforms all others. For this, a parametric graph theory and matrix approach was employed to rank the composites of the best group, revealing that the UHMWPE/SP composite with 1\% (by wt.) of $\mathrm{Si}_{12} \mathrm{O}_{30} \mathrm{Mg}_{8}(\mathrm{OH})_{4}\left(\mathrm{H}_{2} \mathrm{O}\right)_{4} \cdot 8 \mathrm{H}_{2} \mathrm{O}$ and irradiated with $50 \mathrm{kGy}$ of irradiation dose was the most suitable choice of all existing alternatives tested in this study. Although this is the first attempt, to the best of our knowledge, where a smart approach using multivariate calculus and decision-making tools was utilized for figuring the best UHMWPE composite formulation along with appropriate treatment dose, the results and methodology could be extended for any polymer of industrial scale, such as those used in medical implants, defense armor, bulletproof jackets, etc.

Keywords: polymer composites; UHMWPE; clay; gamma irradiation; multivariate statistics; graph theory

\section{Introduction}

Designing and preparing polymer nanocomposites with enhanced and/or novel characteristics for a number of engineering applications is the most captivating research topic in recent years [1]. The engineering applications of and the industries with great interest in the mechanization and commercialization of polymer nanocomposites (PC) include automotive, packaging, electronics, energy, etc. [2]. Furthermore, these PCs have the potential of resolving environmental and medical issues [3]. PCs are the combination of the target polymer matrix and the fillers of a nano/micro scale in a predetermined amount that are uniformly distributed within the polymer matrix. The formulation of 
industrial-scale polymer composites with outstanding physical and chemical properties is a topic of great interest in recent years due to their extensive use in a number of industrial applications [4]. Among these industrial-scale high strength polymers, ultrahigh molecular weight polyethylene (UHMWPE) represents the gold standard because of its broad spectrum of notable properties, including its superior oxidation strength, outstanding resistance to wear, excellent biocompatible nature, exceptional strength (mechanical and chemical), and superb resistance to impact. In addition, its properties can be enhanced while creating crosslinking network within the matrix of UHMWPE [5-10].

However, the wear during its service life in any industrial application is a major threat, and it is well established that oxidation degradation is responsible for the decrease in the wear resistance of UHMWPE. Constant efforts, therefore, are being undertaken to address this issue-i.e., to enhance the oxidation strength of UHMWPE while eliminating/minimizing the possibility of oxidation-induced degradation reactions. These efforts include the modification of UHMWPE with various chemical and physical methods, such as treating it with ionization radiation [11-14], modifying it with peroxide-induced thermochemical reactions [15], altering its properties with silane crosslinking in a moisture rich environment [16], and introducing compatible fillers. The fillers are used for enhancing UHMWPE's properties, most importantly its oxidation strength and crosslinking yield, while quenching/eliminating/reacting with polyethylene free radicals which are induced during the treatment or service of UHMWPE-based components or devices. Vitamin E, vinyl triethoxysilane, methyl triethoxysilane, graphene, and multiwall carbon nano tubes are the most commonly used fillers for UHMWPE [16-18]. These fillers are used for the formation of UHMWPE composites, which are then irradiated with high energy radiation, such as gamma rays, e-beams, etc., for obtaining highly crosslinked stabilized UHMWPE composites. The concentrations of fillers are usually taken as low as possible (i.e., of ppm level), while radiation doses from 25 to $100 \mathrm{kGy}$ are reported to be appropriate for better oxidation resistance and maximum crosslinking yield [19]. Although UHMWPE composites with the above-mentioned fillers have shown excellent performance, the competitive role between fillers stabilizing reactions and fillers crosslinking reactions is a major issue. Therefore, efforts are still in progress to find a more promising alternative that can not only enhance the oxidation strength of UHMWPE but can also make the crosslinking network denser to result in a UHMWPE composite with an improved set of mechanical, electrical, optical, thermal, structural, heat resistant, and biological properties for various industrial applications [20-23]. Furthermore, the optimized value of absorbed dose with the new filler must also be determined to prove the superiority of a new alternative to existing ones.

In this regard, a UHWMPE composite with surface functionalized magnesium silicate hydrous $\left(\mathrm{Si}_{12} \mathrm{O}_{30} \mathrm{Mg}_{8}(\mathrm{OH})_{4}\left(\mathrm{H}_{2} \mathrm{O}\right)_{4} \cdot 8 \mathrm{H}_{2} \mathrm{O}\right)$ seems to be a suitable alternative because $\mathrm{Si}$ and $\mathrm{Mg}$, along with $\mathrm{OH}$ groups, are present in its constituents. Moreover, it is modified with silane, which can play a role in enhancing the crosslinking yield via Si-O-Si linkage and the Si-O grafting extension reaction on irradiation, thus resulting in a UHMWPE composite with superior oxidation strength and improved crosslink density. The silanemodified magnesium silicate hydrous, which is also known as modified SP, has been used recently with LLDPE, LDPE, and HDPE. It is treated with vinyl triethoxysilane for surface modification to improve its compatibility and dispersion. For example, Gul et al. [24] used SP in LLDPE/magnesium hydroxide composites to enhance the thermal withstanding of LLDPE and found that SP can be used with magnesium hydroxide for the formulation of halogen-free flame retardant materials. In another study, Zhang et. al. [25] explored the effect of adding PSPHD-modified SP nano fibers on the properties of LDPE and found specific improvements in the tensile and storage moduli ( $\left.\mathrm{E}^{\prime}\right)$ of LDPE. Recently, Farshchi and Ostad [26] used SP as nano fillers to improve the properties of recycled HDPE and revealed that the addition of SP has positive effects on the properties of recycled contents. This study has concluded that SP can be used as a low-cost reinforcement filler for the recycling industry. However, despite the excellent performance of SP as a filler for the polyethylene family, it has not been used until now, to the best of our 
knowledge, for enhancing the properties of UHMWPE. UHMWPE is usually irradiated with an irradiation dose for enhancing the crosslinking yield within the PE matrix; however, this radiation treatment is also responsible for the oxidation degradation of UHMWPE due to the reaction of radiation-induced free radicals with diffused oxygen, thus reducing the oxidation strength of UHMWPE. The industrial and scientific communities concerned with UHMWPE research and applications are mainly interested in increasing the oxidation strength as well as the crosslinking yield.

This particular study aims to investigate this versatile filler for the exceptional polymer UHMWPE to further enhance the Gx and reduce the OI on gamma treatment, since radiation-induced free radicals (which are left behind) are the major precursors for oxidation degradation reactions, and modified SP has the potential to quench them with grafting extension reactions and siloxane linkage reactions. To explore the effect of the sepiolite concentration and absorbed dose in reducing the oxidation index (OI) and enhancing crosslinking density $(\mathrm{Gx})$, correlation analysis was performed, which is the first and foremost reason to use modified sepiolite as a filler in UHMWP-i.e., to stop/eliminate/minimize the oxidation degradation in UHMWPE, while allowing for radiation-induced free radicals to play a role in enhancing the crosslinking yields. Subsequent to confirmation that modified sepiolite is the filler of choice for UHMWPE, hierarchy cluster analysis and principal component analysis (PCA) were applied to arrange the set of samples into a group having superior oxidation strength and higher crosslinking yield Gx. Finally, a decision-making technique was utilized to determine the best sample-i.e., the UHMWPE/SP composite with superior oxidation strength (minimum OI) and maximum crosslinking yield.

\section{Materials and Methods}

\subsection{Materials}

For the preparation of test specimens, different chemicals and materials were used. The properties of UHMWPE and SP used in this study are tabulated in Table 1 below.

Table 1. Notable properties of UHMWPE and SP.

\begin{tabular}{|c|c|}
\hline \multicolumn{2}{|c|}{ Ultrahigh Molecular Weight Polyethylene (UHMWPE) } \\
\hline Function & Polymer resin \\
\hline Empirical formula & $\left(-\mathrm{CH}_{2}-\mathrm{CH}_{2}-\right) \mathrm{n}$ \\
\hline Density & $0.927 \mathrm{~g} / \mathrm{mL}$ \\
\hline Melting point & $130-136^{\circ} \mathrm{C}$ \\
\hline Molecular weight & 3-6 million gmol $^{-1}$ \\
\hline Melt flow rate (MFI) & $0.05 \mathrm{~g} / 10 \mathrm{~min}$ \\
\hline Physical state & Powder \\
\hline \multicolumn{2}{|c|}{ Magnesium silicate hydrous or SP } \\
\hline Function & Clay filler \\
\hline Empirical formula & $\mathrm{Si}_{12} \mathrm{O}_{30} \mathrm{Mg}_{8}(\mathrm{OH})_{4}\left(\mathrm{H}_{2} \mathrm{O}\right)_{4} \cdot 8 \mathrm{H}_{2} \mathrm{O}$ \\
\hline Surface area & $300 \mathrm{~m}^{2} / \mathrm{g}$ \\
\hline Molecular weight & $613.82 \mathrm{gmol}^{-1}$ \\
\hline Physical state & Powder \\
\hline
\end{tabular}

\subsection{Modification of SP and Composite Preparation}

In order to make SP compatible with UHMWPE, it was modified first by following the reported procedure. The details of the modification procedure can be found elsewhere [27]. Briefly, a predetermined amount of SP was mechanically stirred in water at room temperature for $24 \mathrm{~h}$, filtered and dried at around $90^{\circ} \mathrm{C}$, and ground to a fine powder for further modification. After this, dried ground SP was dispersed in isopropanol and mechanically stirred at room temperature for $30 \mathrm{~min}$. Subsequently, a predetermined amount of vinyl triethoxysilane and HCL was added dropwise, and the admixture was further stirred for approximately $6-8 \mathrm{~h}$ at around $70^{\circ} \mathrm{C}$. Finally, the suspension was filtered, washed, and vacuum dried at $50^{\circ} \mathrm{C}$ for $48 \mathrm{~h}$. The resultant dried solid was again ground and used for 
the preparation of composites. For the preparation of homogenized mixing, ball milling of UHMWPE and SP was performed by using a Retsch ${ }^{\circledR}$ PM ball milling machine. For this, a $125 \mathrm{~mL}$ vial with 30 balls in each vial was used. The composites of various concentrations were prepared at $200 \mathrm{rpm}$ for $8 \mathrm{~h}$ with an interval time of $60 \mathrm{~s}$.

\subsection{Sheet Preparation and Irradiation}

After the mixing of all constituents in the compounder, sheets of micron thickness were prepared with the help of an automated heating press available at KFUMP, SA. The stepwise procedure for sheet preparation is given below:

Step-1: For sheet preparation, 15-16 g of material was placed between the sandblasted steel plates with a $0.5 \mathrm{~mm}$-thick spacer.

Step-2: Plates were then placed in the hot press at $180{ }^{\circ} \mathrm{C}$ to melt the matrix material under zero bar pressure.

Step-3: After 10-15 min, a pressure of 200 bars was applied for $5 \mathrm{~min}$.

Step-4: Plates were then taken out of the press carefully and cooled to room temperature under pressure.

Step-5: After cooling to room temperature, the sheets were removed and cut into small pieces $2 \mathrm{~cm}$ wide and $10 \mathrm{~cm}$ long.

Step-6: Finally, specimens were labeled according to the information given in Table 2.

Table 2. Representation of sample codes with filler concentration.

\begin{tabular}{ccc}
\hline Sample Codes/Label & Concentration of UHMWPE & Concentration of SP \\
\hline PE & $100 \mathrm{wt} \%$ & - \\
PE-S1 & $99 \mathrm{wt} \%$ & $1 \mathrm{wt} \%$ \\
PE-S2 & $98 \mathrm{wt} \%$ & $2 \mathrm{wt} \%$ \\
PE-S3 & $97 \mathrm{wt} \%$ & $3 \mathrm{wt} \%$ \\
\hline
\end{tabular}

Subsequent to the formation of sheets, the composites were irradiated with an irradiation dose of $25 \mathrm{kGy}$ and $50 \mathrm{kGy}$, respectively. Irradiation services were carried out in the open air at Alshifa Irradiation Services, SA, while using Co-60 gamma irradiation at a dose rate of $6.52 \mathrm{kGy} / \mathrm{h}$. To represent the irradiation dose received by each sample, superscripts with the sample code given in Table 2 were used-i.e., PE-S2 ${ }^{25}$ was used for UHMWPE samples containing $2 \%$ SP and irradiated with $25 \mathrm{kGy}$ of irradiation dose.

\subsection{Characterization and Analysis}

The infrared spectroscopy of pure UHMWPE and UHMWPE/SP composites was performed in total attenuated reflectance mode using a Nicolet FTIR spectrophotometer from the Thermo Electron Corporation, Waltham, MA, USA. All the spectra were taken from 400 to $4000 \mathrm{~cm}^{-1}$ at a resolution of $2 \mathrm{~cm}^{-1}$, and each sample was tested for three to four readings. The spectra were averaged and analyzed for SP and radiation-induced alterations and updates. The values of OI, Xc (\%), and Gx were calculated from their respective absorption bands, as reported in the literature [14-16]. The data were analyzed with the help of a correlation matrix, CA, and PCA to explore the hidden pattern in the data and establish the correlation among the variables. The XLSTATS software (trial version) was used for this purpose. The ranking of composites was performed while using the concepts of graph theory and the adjacency matrix. A user-friendly code in Mathematica was developed for performing the graph theory analysis. The details about the multivariate statistical analysis and graph theory can be found elsewhere [28-30].

\section{Results and Discussion}

Figure 1 represents the FTIR spectra of unirradiated and irradiated pristine UHMWPE, where the irradiation doses are $25 \mathrm{kGy}$ and $50 \mathrm{kGy}$, respectively. The major changes and updates in the FTIR spectra upon the irradiation of UHMWPE and its composites with SP are explained below. 


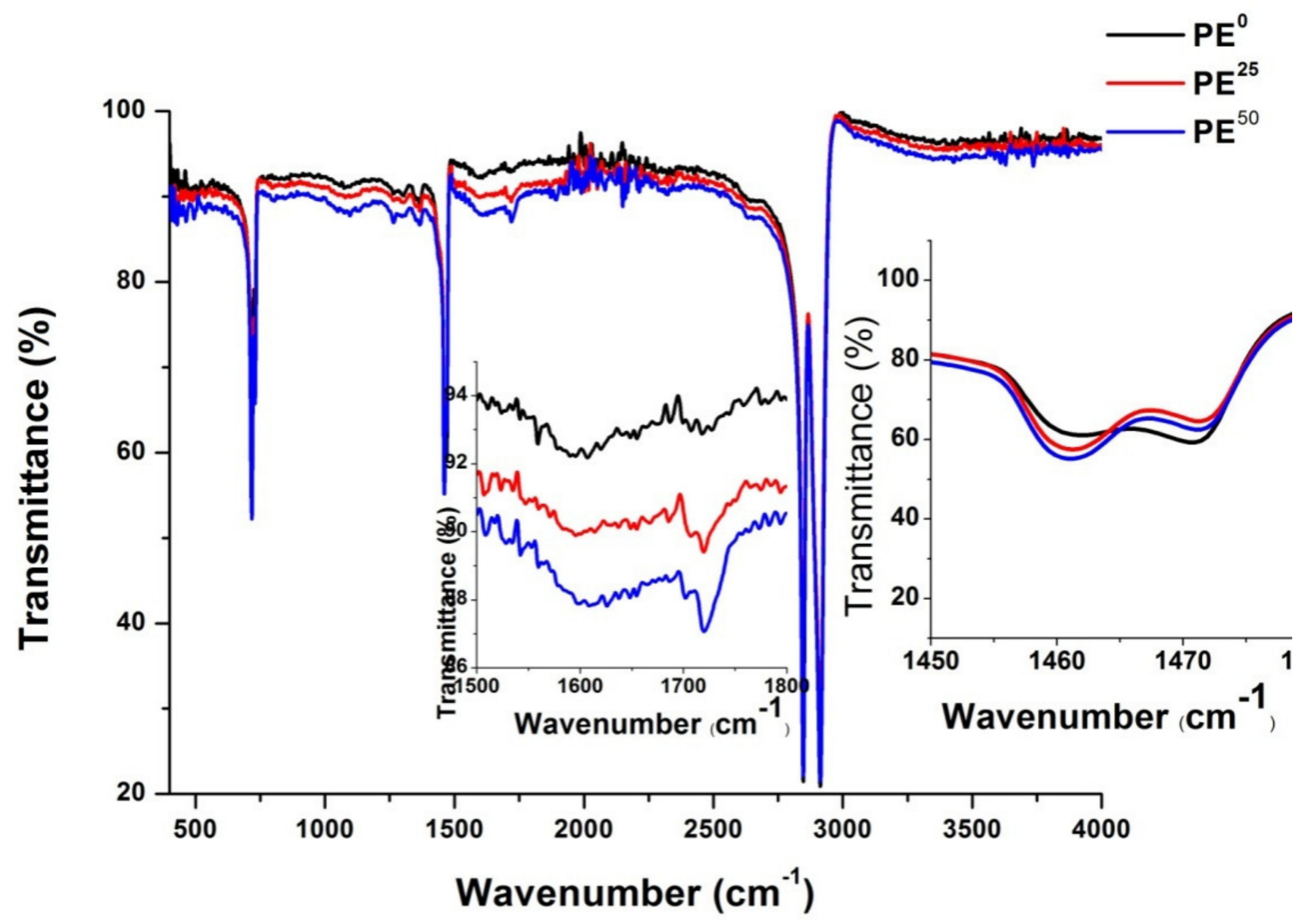

Figure 1. FTIR spectra of unirradiated and irradiated pristine UHMWPE. The specific bands of interest that undergo significant alterations after the incorporation of SP and/or irradiation are given in Table 3 below.

\subsection{Update in the FTIR Spectra of Pristine UHMWPE upon Irradiation}

In order to explore the effect of radiation alone, FTIR analysis of the pristine UHMWPE samples irradiated with $25 \mathrm{kGy}$ and $50 \mathrm{kGy}$ was performed and is represented in Figure 1. The unirradiated sample is represented with PE0, while the rest are represented in accordance with the subjected irradiated doses-i.e., PE25 and PE50, respectively. The qualitative analysis of the prime absorptions of PE in various IR areas with the band assignments is shown in the inset of the figure. A clear view of the spectra discloses that the following variations were induced in UHMWPE because of irradiation:

- Increase in absorbance at $1718 \mathrm{~cm}^{-1}$ with absorbed e-beam dose, which belongs to carbonyl functional groups and is used for the quantitative measure of PE degradation in terms of OI.

- Increase in ratio of absorbance area between 1450 and $1480 \mathrm{~cm}^{-1}$ to the absorption peak area between 2800 and $2950 \mathrm{~cm}^{-1}$-i.e., A1450-1480/A2800-2950, which belongs to crosslinking density.

- Decrease in the ratio of absorbance peak area around $1896 \mathrm{~cm}^{-1}$ to the absorption peak area $1305 \mathrm{~cm}^{-1}$, which is used for the calculation of percentage values of crystallinity $\left(X_{c}\right)$ in each sample.

All values are tabulated in Table 4 below and further used for establishing the correlation matrix for pure UHMWPE to confirm the efficacy of modified sepiolite as a potential filler for the subject matter of interest. 
Table 3. Infrared absorption bands of interest.

\begin{tabular}{cc}
\hline IR Absorption Band/Area & Description \\
\hline $440 \mathrm{~cm}^{-1}$ & Si-O-Mg absorption band [31] \\
$456 \mathrm{~cm}^{-1}$ & O-Si-O bending vibrations [31] \\
$976 \mathrm{~cm}^{-1}, 1014 \mathrm{~cm}^{-1}, 1210 \mathrm{~cm}^{-1}$ & O-Si-O stretching vibrations [31] \\
$1081 \mathrm{~cm}^{-1}$ & Si-O stretch and Siloxane linkage [32] \\
$1450-1480 \mathrm{~cm}^{-1}$ & $\mathrm{CH}_{2}$ bending vibration area [32] \\
$1500-1700 \mathrm{~cm}^{-1}$ & $\mathrm{C}=\mathrm{C}$ estimation area [25] \\
$1720 \mathrm{~cm}^{-1}$ & Carbonyl estimation band [10] \\
$2880-2950 \mathrm{~cm}^{-1}$ & $\mathrm{CH}_{2}$ stretching vibration area [32] \\
$3000-3750 \mathrm{~cm}^{-1}$ & Peroxide bond area [10] \\
$3536 \mathrm{~cm}^{-1}$ & Edged Mg-OH stretching [31] \\
\hline
\end{tabular}

Table 4. Calculated important structural parameters from FTIR results.

\begin{tabular}{|c|c|c|c|c|c|c|c|c|c|}
\hline \multirow{2}{*}{ Rad. Dose kGy } & \multicolumn{2}{|r|}{ PE } & \multicolumn{2}{|r|}{ PE-S1 } & \multicolumn{2}{|r|}{ PE-S2 } & \multicolumn{3}{|c|}{ PE-S3 } \\
\hline & OI & Xc (\%) & Gx OI & Xc (\%) & Gx OI & Xc (\%) & Gx OI & Xc (\%) & Gx \\
\hline 0 & 1.06 & 65.36 & 0.101 .02 & 68.4 & 0.020 .09 & 67.81 & 0.031 .08 & 68.65 & 0 \\
\hline 25 & 2.92 & 62.50 & 0.112 .91 & 67.5 & 0.182 .89 & 69.09 & 0.182 .89 & 73.38 & 0.19 \\
\hline 50 & 3.65 & 63.11 & 0.122 .72 & 67.9 & 0.172 .89 & 68.89 & 0.172 .89 & 67.14 & 0.18 \\
\hline
\end{tabular}

\subsection{Update in the FTIR Spectra upon the Incorporation of Modified SP}

Figure 2a represents the FTIR spectra for unirradiated UHMWPE and its composites. The following significant alterations are evident in the spectra upon the incorporation of SP and/or the increase of its concentration:

- An evident Si-O-Mg starching absorption peak at $440 \mathrm{~cm}^{-1}$ and around an $18 \%$ increase in the absorption at this peak position on increasing the SP concentration from $1 \%$ to $3 \%$ by wt.

- An increase in absorption at $456 \mathrm{~cm}^{-1}, 976 \mathrm{~cm}^{-1}, 1018 \mathrm{~cm}^{-1}, 1210 \mathrm{~cm}^{-1}$, and $1080 \mathrm{~cm}^{-1}$ which belongs to $\mathrm{O}-\mathrm{Si}-\mathrm{O}$ stretching and bending vibration.

- Origination of Si-O stretching vibration at $1080 \mathrm{~cm}^{-1}$ and weak shoulder due to the stretching $\mathrm{Mg}-\mathrm{OH}$ vibration (clearer for 3\% SP by wt.) at $3520 \mathrm{~cm}^{-1}$.

- In addition to these, the characteristics of polyethylene rocking, bending, and stretching bands of $-\mathrm{CH}_{2}$ group at $717 \mathrm{~cm}^{-1}, 730 \mathrm{~cm}^{-1}, 1460 \mathrm{~cm}^{-1}, 1470 \mathrm{~cm}^{-1}, 2849 \mathrm{~cm}^{-1}$, and $2924 \mathrm{~cm}^{-1}$ are evident in pristine UHMWPE as well as unirradiated and irradiated UHMWPE/SP composites.

- Furthermore, there are two additional peaks at $1650 \mathrm{~cm}^{-1}$ and $1720 \mathrm{~cm}^{-1}$ for UHMWPE/SP composites; however, the peak which is positioned at $1650 \mathrm{~cm}^{-1}$ is missing for pristine UHMWPE. Although the absorption at $1720 \mathrm{~cm}^{-1}$ is negligibly small for the pristine UHMWPE sample, for $3 \%$ SP, absorption at this peak position increases by around $20 \%$. The absorption peak at $1720 \mathrm{~m}^{-1}$ (which belongs to products having $\mathrm{C}=\mathrm{O}$ functional groups) is normally used as a marker for polyethylene oxidation degradation [16], thus confirming the fact that oxidation degradation occurs without irradiation, and the number of oxidation products is higher for the sample containing SP.

The peak at $1650 \mathrm{~cm}^{-1}$ belongs to the $\mathrm{OH}$ bending vibration of water molecules attached to SP. The preparation of composite sheets at an elevated temperature and pressure is the reason for the slight shift of this peak towards the lower wavenumber-i.e., from $1656 \mathrm{~cm}^{-1}$ to $1650 \mathrm{~cm}^{-1}$, as it is documented in the literature that the thermal treatment of natural SP is responsible for shifting these zeolitic water $\mathrm{OH}$ peaks toward a lower wavenumber [31]. The probability of free radical generation during the process of the hot pressing and cooling of UHMWPE powder might be the reason for initiating the oxidation chain reactions. This is because these radicals immediately (after their generation) react with diffused oxygen, thus leaving behind the $\mathrm{C}=\mathrm{O}$ functional groups having a 
peak position at around $1720 \mathrm{~cm}^{-1}$. The generation of polyethylene free radicals due to mechanical stress and/or increasing the polyethylene chain mobility, as reported in the literature [33], is also in agreement with our explanation here. The higher amount of oxidation product in the UHMWPE/SP composite might be due to the contribution of two -OH groups attached with the " $\mathrm{ii}^{\prime}$ atom of vinyl triethoxysilane. These are added to the structure of SP during the process of modification to make it compatible with UHMWPE. The $20 \%$ increase in the concentration of oxidation products, as evident in Figure 2a, along with the structure of vinyl triethoxysilane-modified SP reported in the literature [27] also support the above-mentioned explanation.

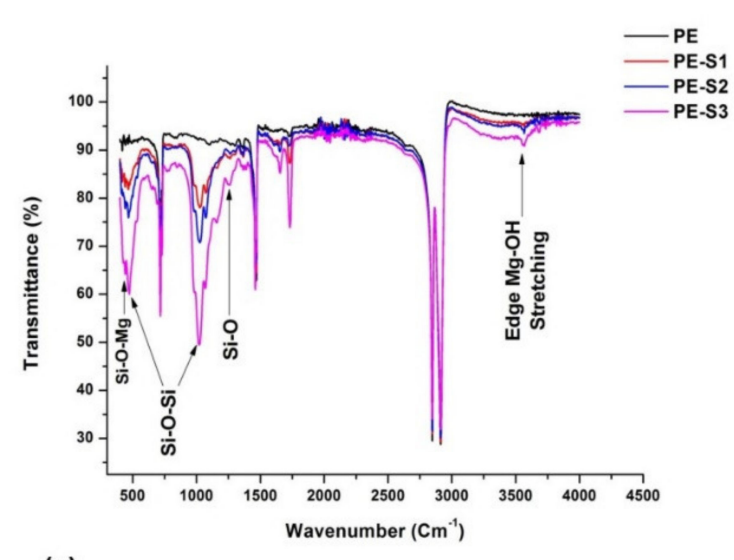

(a)

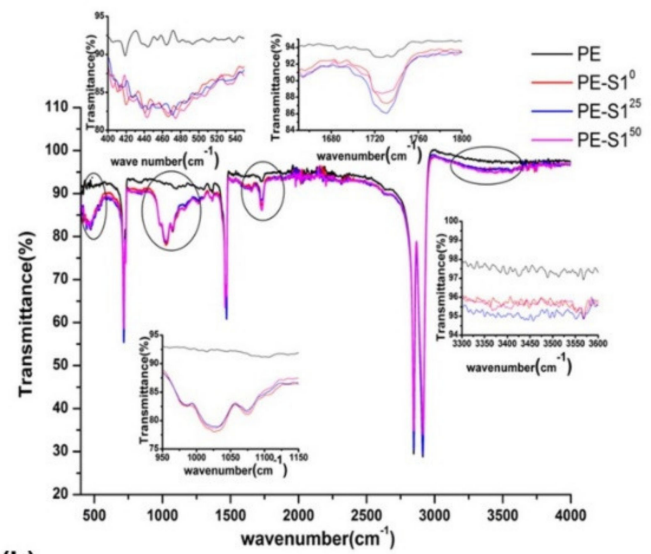

(b)
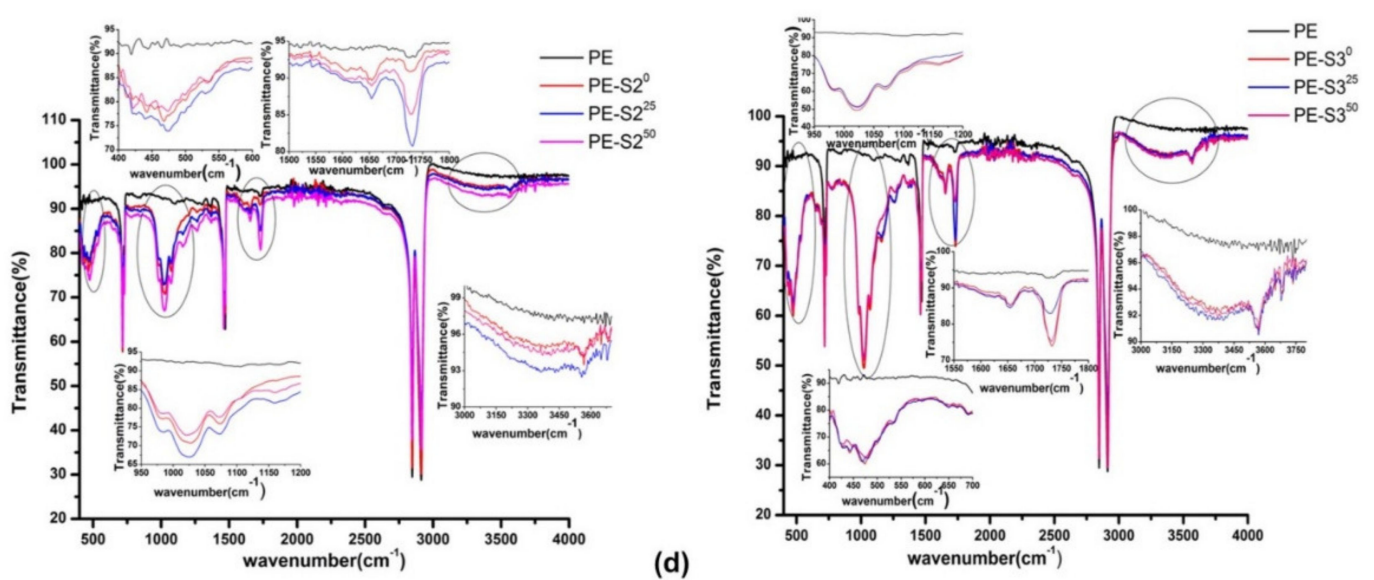

Figure 2. FTIR spectra of (a) unirradiated UHMWPE and UHMWPE/SP composites with (b) $1 \%$ of SP concentration, (c) $2 \%$ of SP concentration, and (d) 3\% of SP concentration.

\subsection{Update in FTIR Spectra upon Irradiation in the Presence of SP}

Figure $2 \mathrm{~b}-\mathrm{d}$ are the FTIR spectra of the UHMWPE/SP composites containing $1 \%, 2 \%$, and 3\% SP and irradiated with $25 \mathrm{kGy}$ and $50 \mathrm{kGy}$ of irradiation doses, respectively. The following significant alterations are evident in the spectra upon irradiating the composite in the presence of SP:

- An increase in the area under the absorption of the $\mathrm{C}=\mathrm{O}$ functional group, having a peak around $1720 \mathrm{~cm}^{-1}$ (area under this peak is used as identification for oxidation degradation of polyethylene [32]) with dose. This increase is around 2\% for PE-SP1, $10 \%$ for PE-SP2, and 18\% for PS-SP3, respectively.

- An increase in absorption under $-\mathrm{CH}_{2}$ bending and stretching vibrations with the dose. These are the characteristics of polyethylene absorption bands, and according to reported literature [14-16], the ratio of $-\mathrm{CH} 2$ bending to stretching vibrations is used as the quantitative measure of crosslink density Gx [16,32]. 
- A significant alteration in the ratio of the area under $1896 \mathrm{~cm}^{-1}$ absorption to $1305 \mathrm{~cm}^{-1}$ with the radiation treatment. These alterations are dependent on the concentration of $\mathrm{SP}$ as well as the absorbed dose.

- An increase in the absorption under the peaks centered at $978 \mathrm{~cm}^{-1}, 1014 \mathrm{~cm}^{-1}$, and $1080 \mathrm{~cm}^{-1}$, which belongs to O-Si-O stretching, Si-O stretching, and siloxane linkage absorption. The increase in absorption due to irradiation is small for PE-SP1, adequate for PE-SP2, and negligible for PE-SP3, as evident from the insets of Figure $2 b-\mathrm{d}$.

- Among other significant alterations is the increase in absorption under the peroxidebonded region and edged $\mathrm{Mg}-\mathrm{OH}$ stretching vibration peak, and this increase is higher for the gamma irradiated PE-SP3 composite.

The well-established free radical chemistry of irradiated polyethylene [34-36] is used to explain the aforementioned structural alteration of composites after gamma irradiation. The primary free radicals generated due to irradiation immediately react while extracting the hydrogen atom from the main polyethylene chain or from $\mathrm{OH}$ group of silane attached to the modified SP, thus responsible for enhancing the crosslinking yield. Another possibility is the reaction of polyethylene free radicals with diffused oxygen, which results in the initiation of oxidation chain reactions, thus increasing the values of oxidation index (OI) and altering the percent crystallinity of UHMWPE. From trends evident from the figure and explained above, it is clear that composites are affected by both types of reaction paths upon treating with the irradiation dose $[35,36]$. However, it seems from the figure that PE-SP3 might suffer more via the oxidation degradation reaction path, PE-SP2 is more permeable for silane grafting extension reactions, and the PE-SP1 matrix might be spongier for crosslinking reactions. These facts are also evident from the data shown in Table 4 below.

\subsection{Update in Important Structural Parameters upon Irradiation}

Shown in Table 4 are the values of the oxidation index (OI), percent crystallinity $(\mathrm{Xc})$, and crosslinking density for unirradiated and gamma-irradiated PE, PE-SP1, PE-SP2, and PE-SP3, respectively. These values are calculated while using methods explained in the literature for UHMWPE [14-16]. The general trend, as far as the radiation of composites is concerned, is as expected-i.e., a decrease in the percent crystallinity due to chain scission close to the crystalline lamellae and an increase in OI as well as Gx because of the aforementioned radiation-induced free radicals' crosslinking and oxidation reactions. Overall, the pristine UHMWPE samples suffer more when compared with the composites. However, it is extremely difficult to say conclusively which formulation and dose are preferable on the basis of a single parameter-i.e., OI, Gx, and $\mathrm{Xc}_{\mathrm{c}}$, respectively. Furthermore, it is also very hard to perceive any correlation or dependence of OI, Gx, and $\mathrm{Xc}_{\mathrm{c}}(\%)$ on the absorbed dose in terms of considering a single parameter. In order to determine the solution for such multivariable problems, there are two methods. The first is to do series of experiments while keeping one variable constant and varying others to reach a conclusive combination of all parameters-i.e., minimum OI, maximum Gx, the possible lowest amount of SP concentration, and the appropriate radiation dose, respectively. The second is to use some smart approaches and methods, such statistical methods, multivariate calculus, artificial intelligence (AI) [37-40], or any robust multicriteria decision-making techniques, to determine the hidden pattern in multidimensional data and to obtain the optimized solution for the problem. Therefore, correlation analysis was performed to reveal the effectiveness of SP as a suitable filler for UHMWPE. Multivariate statistical analysis of data was performed to determine the active variables responsible for grouping the alternatives with superior oxidation strength and higher crosslinking yield. Finally, parametric graph theory was applied to choose the best among all existing alternatives that have superior oxidation strength and crosslink density, within the constraint that the amount of filler is as low as possible for achieving the maximum crosslink density and higher oxidation strength. 


\subsection{Analysis for Correlation}

Shown in Table 5 is the correlation of the UHWWPE structural parameters with the radiation dose. It is evident from the correlation data that OI is positively correlated (strong, with value of 0.97 ) with radiation dose. This means that oxidation is higher when UHMWPE is irradiated with a higher dose, thus implying that the oxidation strength of UHMWPE is under serious threat with the increasing value of gamma dose. Table 6 represents the correlation matrix of the composite's structural parameters SP concentration and the absorbed dose to provide clearer insight into the effect of radiation treatment in the presence of filler (i.e., SP). This analysis is performed to explore the effect of sepiolite concentration and the absorbed dose on reducing the $\mathrm{OI}$ and enhancing the crosslinking density Gx. This confirms the efficacy of modified clay as a potential filler for UHMWPE, since the moderate negative correlation of OI $(-0.46)$ and the strong positive correlation of crosslink density Gx (0.87) with the radiation dose is evident from the correlation matrix (Table 6). This is the main reason for using modified sepiolite as a filler in UHMWPEi.e., to stop/eliminate/minimize the oxidation degradation in UHMWPE. The possibility of radiation-induced free radical reactions with the $\mathrm{OH}$ group (rather than diffused oxygen) of silane attached to the surface of $\mathrm{SP}$ is the reason for enhancing the crosslinking yields and reducing the oxidation degradation, as confirmed by the correlation matrix analysis. The correlation analysis also depicts the positive effects of SP incorporation, as there is a weak to moderate positive correlation of OI, $X_{\mathrm{C}}(\%)$, and Gx with SP concentration. The negative correlation of $\mathrm{OI}$ with $\mathrm{Gx}$, as evident from this correlation analysis (see the last entry of the third column), is in total agreement with the well-reported radiation chemistry of polyethylene [36]. Subsequent to confirming that modified sepiolite is the filler of choice for UHMWPE, the next step is to determine which amount of filler and dose combination is more suitable for achieving the ultimate aim. For this hierarchy cluster analysis, principal component analysis (PCA) and a parametric graph theory and matrix approach are utilized to determine the best among all existing UHMWPE/SP alternatives. All the methodologies are discussed in the proceeding sections.

Table 5. Correlation matrix of pristine unirradiated and irradiated UHMWPE for in-depth investigation of the correlation of radiation dose with OI, $X_{c}(\%)$, and Gx.

\begin{tabular}{ccccc}
\hline & Dose & OI & Xc (\%) & Gx \\
\hline Dose & 1 & & & \\
OI & 0.9697 & 1 & & \\
Xc (\%) & -0.7468 & -0.8866 & 1 & 1 \\
Gx & 1 & 0.9697 & -0.7468 & \\
\hline
\end{tabular}

Table 6. Correlation matrix for in-depth investigation of dose and SP concentration on the OI, Xc (\%), and Gx.

\begin{tabular}{cccccc}
\hline & Dose & SP Conc. & OI & Xc(\%) & Gx \\
\hline Dose & 1 & & & & \\
SP Conc. & 0.22 & 1 & & & \\
OI & -0.46 & 0.25 & 1 & & \\
Xc (\%) & 0.02 & 0.46 & 0.10 & 1 & 1 \\
Gx & 0.87 & 0.26 & -0.25 & 0.28 & 1 \\
\hline
\end{tabular}

\subsection{Cluster Analysis}

Figure 3 shows the dendrogram obtained from the hierarchy cluster analysis, which generated three groups of UHMWPE/SP composites on the basis of similar characteristic features. Groups 1, 2, and 3 correspond to relatively low, moderate, and best, respectively, as far as oxidation strength and crosslinking density of composites is concerned. According to the dendrogram, unirradiated composites constitute the first group; i.e., Group 1 is the low standard group on a relative scale (see Figure 3). Group 2 consists of the standalone 
composite PE-S3 ${ }^{25}$ and is of a moderate level on the relative scale. The lowest value of Gx (see Table 4) is the reason for separating this particular composite from the other members of the list. This standalone moderate standard group is followed by a group of five composites, which form the best cluster of composites on a relative scale. The similarities in the values of properties (more specifically, OI and Gx) are responsible for arranging the five composites (i.e., $\mathrm{PE}-\mathrm{S} 2^{50}, \mathrm{PE}-\mathrm{S} 1^{50}, \mathrm{PE}-\mathrm{S} 3^{50}, \mathrm{PE}-\mathrm{S} 1^{25}$, and $\mathrm{PE}-\mathrm{S} 2^{25}$ ) to make this the best cluster of composites.

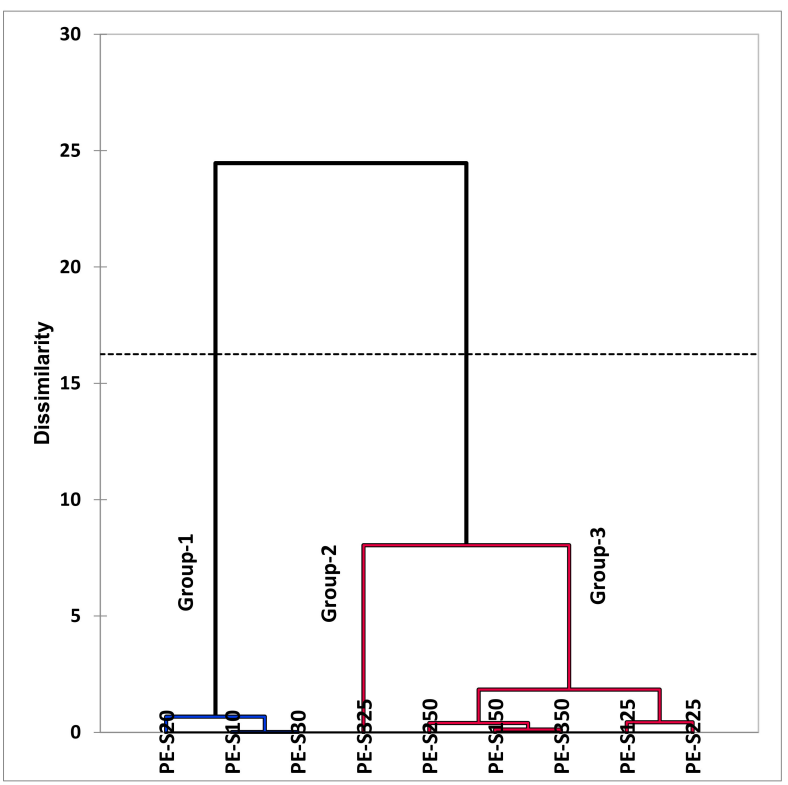

Figure 3. Dendrogram representing the arrangements of composites in groups.

\subsection{Principal Component Analysis (PCA)}

For further confidence of the correlation and cluster arrangement of composites on the basis of SP concentration, absorbed dose, and structural parameters, PCA was performed. For PCA, the structural parameters (i.e., OI, Xc (\%), Gx, and absorbed dose) were taken as active variables, while SP concentration was taken as the active observation. The eigenvalues (obtained after performing PCA) corresponding to the active variable are listed in Table 7, and it is obvious that only the first two sets are sufficient to explain the information contained in the original data. The percentage variance for the first two sets of Eigenvalues is $95 \%$, which is sufficient for classification purposes [28] and confirmed the applicability of PCA with confidence for the analysis of data. PC- 1 shows $69.75 \%$ of total variance with strong positive characteristic loading (i.e., > 0.75) for OI and Gx and weak loading for Xc (\%). The major contributing factor for PC-2 is the $\mathrm{Xc}_{\mathrm{c}}(\%)$, and this PC is responsible for defining $25.88 \%$ of cumulative variance. The weak negative loading of this PC with the absorbed dose, strong positive loading of $X_{\mathrm{c}}(\%)$, and almost negligible small positive loading of OI and Gx (as evident from Table 7) suggests that the major dominating factor for PC-2 is the concentration of SP.

Table 7. Factor loadings of quality parameters.

\begin{tabular}{ccccc}
\hline & PCA-1 & PCA-2 & PCA-3 & PCA-4 \\
\hline Abs. dose & 0.910 & -0.288 & 0.297 & -0.017 \\
OI & 0.976 & 0.043 & -0.180 & -0.115 \\
Xc (\%) & 0.201 & 0.975 & 0.099 & -0.003 \\
Gx & 0.984 & 0.025 & -0.117 & 0.131 \\
Eigenvalue & 2.790 & 1.035 & 0.144 & 0.031 \\
Variability (\%) & 69.748 & 25.883 & 3.603 & 0.766 \\
Cumulative \% & 69.748 & 95.631 & 99.234 & 100 \\
\hline
\end{tabular}


The bipolar plot of the active variables on active observation in the first two PCs is shown in Figure 4, which depicts the influence of the active variable to organize the enlisted nine formulations into three groups of low, moderate, and best composites. Group 2 (which has weak to moderate positive loadings on PC-1 and strong positive loading on PC-2) is strongly influenced by the $X_{C}(\%)$. The best standard group, i.e., Group 3, has moderate to strong positive loading on PC-1 and weak negative loading on PC-2. Furthermore, the members of this group are strongly influenced by OI, Gx, and the absorbed dose (see Figure 3), thus complementing the results of the correlation matrix and cluster analysis.

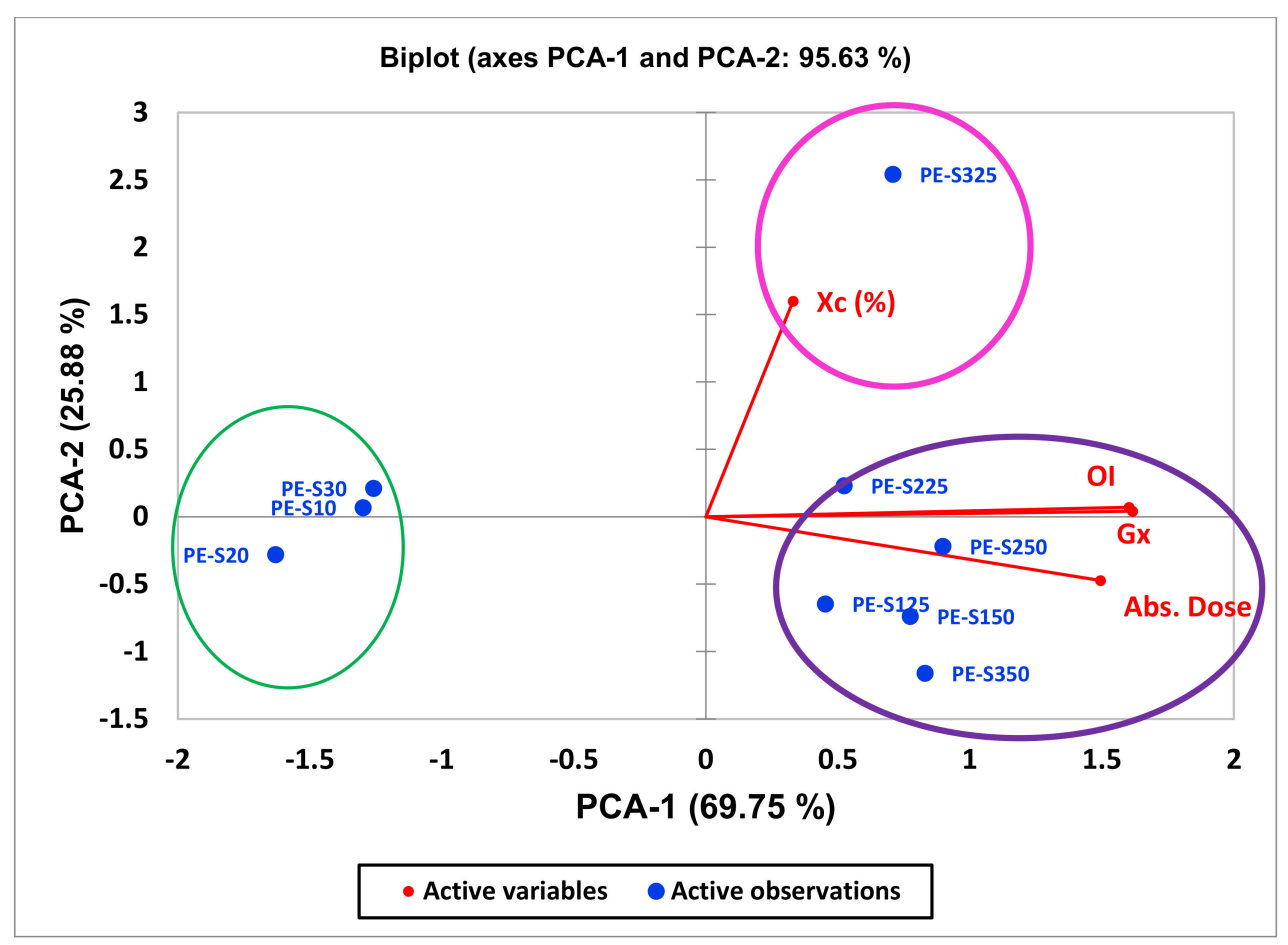

Figure 4. Bipolar PCA plot representing active variables and observations on first two PCs.

Although correlation, cluster, and PCA have confirmed the effectiveness of SP as a filler for enhancing the oxidation strength and crosslink density of UHMWPE, further investigation is still required to determine the best alternative from the list present in the best group. This further investigation is necessary because the amount of filler needs to be as low as possible. There are two approaches to accomplish this task: either to perform a series of experiments that require time and resources, or to use a suitable decisionmaking approach for separating the best alternative on the basis of structural updates in the UHMWPE matrix due to irradiation in the presence of SP. The latter seems to be more appealing because it can effectively save time and reduce cost. Therefore, the concepts of graph, diagraph, and adjacency matrix are used for choosing the more suitable alternative.

\subsection{Composites Ranking Using Graph Theory and Matrix Approach}

In order to do this, the first and foremost task is to determine the higher obligatory valued (HOV) and low obligatory valued (LOV) factors. The HOV factors are those whose lower values are required; for example, in this case, the main reason for incorporating the filler in UHMWPE is to control its oxidation degradation while reducing the $\mathrm{OI}$ and to enhance its crosslink density, i.e., Gx. So, in the course of this study OI and $X_{c}(\%)$ are the LOV factors and Gx is the HOV factor. Subsequent to the identification of LOV and HOV factors, their relative importance needed to be established. This is accomplished with the help of expert opinions and documented literature [14-17]. During the course of this study, experts having experience of more than five years were approached for their opinions and set the relative importance given below: 
- OI and Gx are equally important for the industrial perspective on the applications of UHMWPE and its composites;

- Oxidative stability is more important than $X_{\mathrm{c}}(\%)$, as far as the industrial applications of UHMWPE and its service life are concerned;

- Crosslink density $(\mathrm{Gx})$ is more important than $\mathrm{Xc}_{\mathrm{c}}(\%)$, as far as the industrial applications of UHMWPE and its service life are concerned.

The next step is converting this verbal conversation into numbers and plotting a graph with the parameters as nodes and edges with relative importance, as shown in Figure 5 below. The 11-points fuzzy conversation, explained elsewhere with comprehensive detail [40], is used for the representation of verbal conversation as numbers. The conversion of this diagraph into the adjacency matrix is the next step, with diagonal elements left empty for input. Subsequent to writing the adjacency matrix, the quantitative input data of all alternative parameters are normalized while using the procedure for LOV or HOV factors. The last step is making the decision matrix for each set of data and determining the permanent of this matrix, which are the quantities' measure of index value. In the last step, all the alternatives are ranked according to the ascending order of index values, i.e., a higher index value $\rightarrow 1$ st and so on.

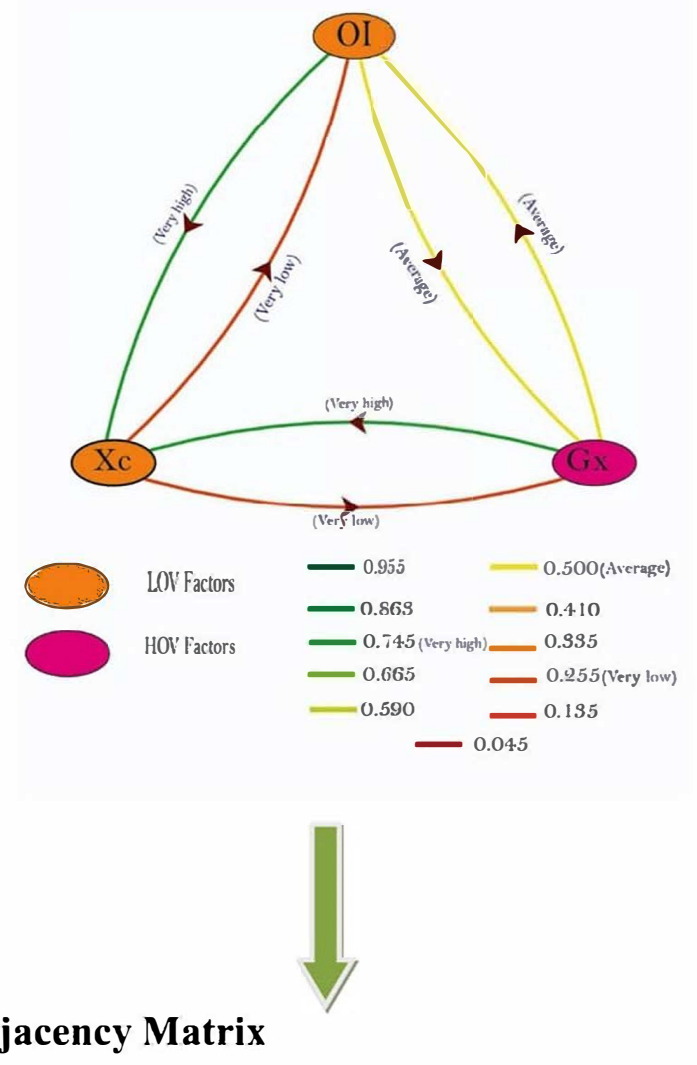

\section{Adjacency Matrix}

$$
\left[\begin{array}{cccc} 
& \mathrm{OI} & \mathrm{Xc}(\%) & \mathrm{Gx} \\
\mathrm{OI} & - & 0.745 & 0.5 \\
\mathrm{Xc}(\%) & 0.255 & - & 0.745 \\
\mathrm{Gx} & 0.5 & 0.255 & -
\end{array}\right]
$$

Figure 5. Composite assessment graph with corresponding adjacency matrix.

The stepwise ranking protocol as explained above for this particular study is given below:

Step-1: Drawing the self-explanatory graph and writing the adjacency matrix. 
Step-2: Writing the quantitative measure of the active variables and normalization.

Quantitative values of active variables

\begin{tabular}{|c|c|c|c|}
\hline Sample Code & Oxidation Index & Crystallinity \% & Crosslinking Density \\
\hline PE-S1 ${ }^{25}$ & 2.91 & 67.46 & 0.181 \\
\hline PE-S1 ${ }^{50}$ & 2.717 & 67.94 & 0.173 \\
\hline PE-S2 50 & 2.894 & 68.89 & 0.179 \\
\hline PE-S3 25 & 2.895 & 73.38 & 0.185 \\
\hline PE-S3 50 & 2.895 & 67.14 & 0.180 \\
\hline
\end{tabular}

Step-3: Normalization while keeping the rule of normalization for LOV and HOV factors.

Normalization

\begin{tabular}{|c|c|c|c|}
\hline Sample & Oxidation Index & Crystallinity \% & Crosslinking Density \\
\hline PE-S1 ${ }^{25}$ & 0.93367698 & 0.07094151 & 0.97837838 \\
\hline PE-S1 ${ }^{50}$ & 1 & 0.9882249 & 0.93513514 \\
\hline PE-S2 ${ }^{50}$ & 0.93883898 & 0.97459718 & 0.96756757 \\
\hline PE-S3 25 & 0.93851468 & 0.91496321 & 1 \\
\hline PE-S3 ${ }^{50}$ & 0.93851468 & 1 & 0.97297297 \\
\hline
\end{tabular}

Step-4: Writing the decision matrix for each set of parameters, the calculation of the permanent for each set, the calculation the suitability index value, and finally ranking the alternatives.

Ranking of Composites

\begin{tabular}{|c|c|c|c|}
\hline Sample Code & $\operatorname{Per}(A)$ & Suitability Index Value (SIV) & Ranking \\
\hline PE-S1 ${ }^{25}$ & 0.755807 & 0.41 & 5 th \\
\hline PE-S1 ${ }^{50}$ & 1.84883 & 1.00 & 1 st \\
\hline PE-S2 ${ }^{50}$ & 1.80116 & 0.97 & $3 r d$ \\
\hline $\mathrm{PE}-S 3^{25}$ & 1.76574 & 0.95 & 4 th \\
\hline PE-S3 $3^{50}$ & 1.83631 & 0.99 & 2nd \\
\hline
\end{tabular}

From the results, it can be seen that PE-S1 ${ }^{50}$, i.e., UHMWPE containing $1 \%$ of SP and irradiated with $50 \mathrm{kGy}$ of irradiation dose, is the best among the enlisted five alternatives of UHMWPE/SP composites. This is the optimized decision and is quite understandable because to keep the minimal effect on the properties of UHMWPE, the concentration of fillers needs to as low as possible. The results and methodology presented in this work consist of reducing the alternatives, intelligently using the cluster and principal components analysis, and considering the possible important active variables for determining the best alternative among all options in more indisputable way.

\section{Conclusions}

UHMWPE composites with surface modified SP were successfully prepared and irradiated with an irradiation dose to enhance their oxidation strength and crosslink density. The composites were characterized with FTIR spectroscopy, and spectra were used for extracting the structural parameters, i.e., OI, $X_{c}(\%)$, and Gx, for unirradiated and irradiated composites. The data were then analyzed with a correlation matrix, CA, PCA, and parametric graph theory for exploring the effectiveness of SP as a filler in order to enhance the oxidation strength and crosslinking yield of UHMWPE. The aforementioned comprehensive and multivariate analysis during the study has concluded the following:

- The incorporation of SP is proven to be an effective filler, as it enhances the oxidation strength and crosslink density, which is confirmed by the negative correlation of OI with the absorbed irradiation dose;

- Irradiating the UHMWPE in the presence of SP resulted in enhancing the crosslinking density, as evident from the strong positive correlation of Gx with the absorbed irradiation dose; 
- Composites having superior oxidation strength and crosslink density are strongly influenced by OI, Gx, and the absorbed dose, as confirmed by CA and PCA;

- The UHMWPE/SP composite containing $1 \%$ (by wt.) of SP and irradiated with 50 kGy of irradiation dose, i.e., PE-SP1 $1^{50}$, was found to be the best choice among the existing alternatives, as confirmed by parametric graph theory analysis.

The results presented in this study are of particular importance when considering the feasibility of using UHMWPE in various industrial applications, where wear due to oxidation degradation is a severe issue. Furthermore, the methodology proposed here could be utilized in any area where the issue of choosing the best alternative among existing options is required.

Funding: This research received no external funding.

Institutional Review Board Statement: Not applicable.

Informed Consent Statement: Not applicable.

Data Availability Statement: Not applicable.

Acknowledgments: The author acknowledges the moral support provided by the King Abdulaziz University, Jeddah 21589, Saudi Arabia to accomplish this research.

Conflicts of Interest: The author declares no conflict of interest associated with this research article.

\section{References}

1. Paul, D.R.; Robeson, L.M. Polymer nanotechnology: Nanocomposites. Polymer 2008, 49, 3187-3204. [CrossRef]

2. Voevodin, A.; O'neill, J.; Zabinski, J. Nanocomposite tribological coatings for aerospace applications. Surf. Coat. Technol. 1999, 116, 36-45. [CrossRef]

3. Amatucci, G.; Pereira, N.; Badway, F.; Sina, M.; Cosandey, F.; Ruotolo, M.; Cao, C. Formation of lithium fluoride/metal nanocomposites for energy storage through solid state reduction of metal fluorides. J. Fluor. Chem. 2011, 132, 1086-1094. [CrossRef]

4. Xu, H.; Kuo, S.-W.; Huang, C.-F.; Chang, F.-C. Poly (acetoxystyrene-co-isobutylstyryl POSS) nanocomposites: Characterization and molecular interaction. J. Polym. Res. 2002, 9, 239-244. [CrossRef]

5. Han, L.; Cai, H.; Chen, X.; Zheng, C.; Guo, W. Study of UHMWPE fiber surface modification and the properties of UHMWPE/epoxy composite. Polymers 2020, 12, 521. [CrossRef]

6. Sharip, N.S.; Ariffin, H.; Yasim-Anuar, T.A.T.; Andou, Y.; Shirosaki, Y.; Jawaid, M.; Tahir, P.M.; Ibrahim, N.A. Melt- vs. Non-Melt Blending of Complexly Processable Ultra-High Molecular Weight Polyethylene/Cellulose Nanofiber Bionanocomposite. Polymers 2021, 13, 404. [CrossRef]

7. Niedzielska, I.; Bakk, M.; Niedzielski, D.; Okła, H.; Gabor, J.; Stanula, A.; Paluch, J.; Swinarew, A.S. Temporomandibular Joint Prostheses: Optimal Materials for the Optimal Stomatognathic System Performance-Preliminary Study. J. Funct. Biomater. 2021, 12, 7. [CrossRef]

8. Hussain, M.; Naqvi, R.A.; Abbas, N.; Khan, S.M.; Nawaz, S.; Hussain, A.; Zahra, N.; Khalid, M.W. Ultra-high-molecular-weightpolyethylene (UHMWPE) as a promising polymer material for biomedical applications: A concise review. Polymers 2020, 12, 323. [CrossRef] [PubMed]

9. Zhang, R.; Wang, S.; Tian, J.; Chen, K.; Xue, P.; Wu, Y.; Chou, W. Effect of PEW and CS on the Thermal, Mechanical, and Shape Memory Properties of UHMWPE. Polymers 2020, 12, 483. [CrossRef]

10. Rocha, M.; Mansur, A.; Mansur, H. Characterization and accelerated ageing of UHMWPE used in orthopedic prosthesis by peroxide. Materials 2009, 2, 562-576. [CrossRef]

11. Naresh Kumar, N.; Yap, S.L.; Bt Samsudin, F.N.D.; Khan, M.Z.; Pattela Srinivasa, R.S. Effect of argon plasma treatment on tribological properties of UHMWPE/MWCNT nanocomposites. Polymers 2016, 8, 295. [CrossRef] [PubMed]

12. Mehmood, M.S.; Tabasam, M.; Ahmed, M.; Idris, A.; Yasin, T.; Ikram, M. Mueller matrix polarimetry for characterization of E-Beam irradiated Uhmwpe. Radiat. Phys. Chem. 2020, 166, 108503. [CrossRef]

13. Mehmood, M.S.; Thira, I.; Idris, A.; Yasin, T.; Ikram, M. UHMWPE band-gap properties-II: Effect of post e-beam irradiation real time shelf aging in air. Radiat. Phys. Chem. 2019, 159, 231-237. [CrossRef]

14. Mukhtar, S.S.; Mehmood, M.S.; Maqbool, S.A.; Ghafoor, B.; Baluch, M.A.; Siddiqui, N.; Yasin, T. Effect of $\gamma$-irradiation on the thermal properties of UHMWPE/MWCNTs nanocomposites: A comparative study of incorporating unmodified and $\gamma$-ray-modified MWCNTs. Bull. Mater. Sci. 2018, 41, 1-8. [CrossRef]

15. Senra, M.R.; Marques, M.d.F.V. Synthetic Polymeric Materials for Bone Replacement. J. Compos. Sci. 2020, 4, 191. [CrossRef]

16. Mehmood, M.S.; Sanawar, A.; Siddiqui, N.; Yasin, T. Quantification of silane grafting efficacy, weak IR vibration bands and percentage crystallinity in post e-beam irradiated UHMWPE. Polym. Bull. 2017, 74, 213-227. [CrossRef] 
17. Gigante, A.; Bottegoni, C.; Ragone, V.; Banci, L. Effectiveness of vitamin-E-doped polyethylene in joint replacement: A literature review. J. Funct. Biomater. 2015, 6, 889-900. [CrossRef]

18. Camacho, N.; Stafford, S.W.; Garza, K.M.; Suro, R.; Barron, K.I. Ultra-high molecular weight polyethylene reinforced with multiwall carbon nanotubes: In vitro biocompatibility study using macrophage-like cells. Lubricants 2015, 3, 597-610. [CrossRef]

19. Premnath, V.; Harris, W.; Jasty, M.; Merrill, E. Gamma sterilization of UHMWPE articular implants: An analysis of the oxidation problem. Biomaterials 1996, 17, 1741-1753. [CrossRef]

20. Chen, X.; Zhang, S.; Zhang, L.; Zhu, P.; Zhang, G. Design and Characterization of the Surface Porous UHMWPE Composite Reinforced by Graphene Oxide. Polymers 2021, 13, 482. [CrossRef]

21. Gong, T.; Curosu, I.; Liebold, F.; Vo, D.M.P.; Zierold, K.; Maas, H.-G.; Cherif, C.; Mechtcherine, V. Tensile Behavior of High-Strength, Strain-Hardening Cement-Based Composites (HS-SHCC) Reinforced with Continuous Textile Made of Ultra-High-MolecularWeight Polyethylene. Materials 2020, 13, 5628. [CrossRef] [PubMed]

22. Visco, A.; Scolaro, C.; Quattrocchi, A.; Montanini, R. Mechanical Characterization of Nanocomposite Joints Based on Biomedical Grade Polyethylene under Cyclical Loads. Polymers 2020, 12, 2681. [CrossRef] [PubMed]

23. Forster, A.L.; Tsinas, Z.; Al-Sheikhly, M. Effect of Irradiation and Detection of Long-Lived Polyenyl Radicals in Highly Crystalline Ultra-High Molar Mass Polyethylene (UHMMPE) Fibers. Polymers 2019, 11, 924. [CrossRef] [PubMed]

24. Gul, R.; Islam, A.; Yasin, T.; Mir, S. Flame-retardant synergism of sepiolite and magnesium hydroxide in a linear low-density polyethylene composite. J. Appl. Polym. Sci. 2011, 121, 2772-2777. [CrossRef]

25. Zhang, Q.-t.; Li, S.-x.; Hu, X.-p.; Wang, P.-j.; Zeng, J.-b.; Wang, X.-1.; Wang, Y.-z. Structure, morphology, and properties of LDPE/sepiolite nanofiber nanocomposite. Polym. Adv. Technol. 2017, 28, 958-964. [CrossRef]

26. Farshchi, N.; Ostad, Y.K. Sepiolite as a nanofiller to improve mechanical and thermal behavior of recycled high-density polyethylene. Prog. Rubberplast. Recycl. Technol. 2020, 36, 185-195. [CrossRef]

27. Shafiq, M.; Yasin, T.; Saeed, S. Synthesis and characterization of linear low-density polyethylene/sepiolite nanocomposites. J. Appl. Polym. Sci. 2012, 123, 1718-1723. [CrossRef]

28. Baluch, M.A.; Hashmi, H.N. Investigating the impact of anthropogenic and natural sources of pollution on quality of water in Upper Indus Basin (UIB) by using multivariate statistical analysis. J. Chem. 2019, 2019, 4307251. [CrossRef]

29. Xiaoqing, S.; Jianmin, B.; Chunpeng, Z.; Yu, W.; Hanli, W.; Zhuo, J. Hydrochemistry characteristics and water quality assessment for irrigation along the second Songhua river in the south of the Songnen Plain, Northeast China. Pol. J. Environ. Stud. 2019, 29, 371-395. [CrossRef]

30. Geană, E.-I.; Ciucure, C.T.; Apetrei, C.; Artem, V. Application of spectroscopic UV-Vis and FT-IR screening techniques coupled with multivariate statistical analysis for red wine authentication: Varietal and vintage year discrimination. Molecules 2019, 24, 4166. [CrossRef]

31. Hojati, S.; Khademi, H. Thermal behavior of a natural sepiolite from Northeastern Iran. J. Sci. Islam. Repub. Iran 2013, 24, 129-134.

32. Shafiq, M.; Mehmood, M.S.; Yasin, T. On the structural and physicochemical properties of gamma irradiated UHMWPE/silane hybrid. Mater. Chem. Phys. 2013, 143, 425-433. [CrossRef]

33. Jahan, M.; Wang, C.; Schwartz, G.; Davidson, J. Combined chemical and mechanical effects on free radicals in UHMWPE joints during implantation. J. Biomed. Mater. Res. 1991, 25, 1005-1017. [CrossRef] [PubMed]

34. Costa, L.; Luda, M.; Trossarelli, L.; Del Prever, E.B.; Crova, M.; Gallinaro, P. Oxidation in orthopaedic UHMWPE sterilized by gamma-radiation and ethylene oxide. Biomaterials 1998, 19, 659-668. [CrossRef]

35. Costa, L.; Bracco, P. Mechanisms of cross-linking, oxidative degradation, and stabilization of UHMWPE. In UHMWPE Biomaterials Handbook; Elsevier: Amsterdam, The Netherlands, 2016; pp. 467-487.

36. Bhagat, S.K.; Paramasivan, M.; Al-Mukhtar, M.; Tiyasha, T.; Pyrgaki, K.; Tung, T.M.; Yaseen, Z.M. Prediction of lead (Pb) adsorption on attapulgite clay using the feasibility of data intelligence models. Environ. Sci. Pollut. Res. 2021, $2021,83$.

37. Roshani, M.; Phan, G.T.; Ali, P.J.M.; Roshani, G.H.; Hanus, R.; Duong, T.; Corniani, E.; Nazemi, E.; Kalmoun, E.M. Evaluation of flow pattern recognition and void fraction measurement in two phase flow independent of oil pipeline's scale layer thickness. Alex. Eng. J. 2021, 60, 1955-1966. [CrossRef]

38. Tajmiri, S.; Azimi, E.; Hosseini, M.R.; Azimi, Y. Evolving multilayer perceptron, and factorial design for modelling and optimization of dye decomposition by bio-synthetized nano CdS-diatomite composite. Environ. Res. 2020, 182, 108997. [CrossRef]

39. Roshani, M.; Phan, G.; Roshani, G.H.; Hanus, R.; Nazemi, B.; Corniani, E.; Nazemi, E. Combination of X-ray tube and GMDH neural network as a nondestructive and potential technique for measuring characteristics of gas-oil-water three phase flows. Measurement 2021, 168, 108427. [CrossRef]

40. Kunitz, S.; Markee, N. Understanding the fuzzy borders of context in conversation analysis and ethnography. In Discourse and Education: Encyclopedia of Language and Education (3. vyd., s. 15-27); Springer: Cham, Switzerland, 2017. 